\title{
A LÍNGUA PORTUGUESA NO ENSINO MÉDIO: CONTEÚDOS DE ENSINO E O DESENVOLVIMENTO DA AULA
}

\author{
Célia Maria Medeiros BARBOSA DA SILVA* \\ João Gomes da SILVA NETO**
}

- RESUMO: Neste artigo, apresentamos algumas reflexões sobre o lugar da língua como conteúdo de ensino na aula de língua portuguesa, conforme pode ser observada em situações concretas. A investigação segue uma vertente de pesquisas que, na confluência dos estudos da linguagem e da educação, busca respostas para uma problemática envolvendo as atuais políticas públicas brasileiras para a educação, a formação docente e os estudos sobre o ensino da língua materna, em face da imperativa necessidade de melhoria dos atuais níveis de alfabetização e letramento de crianças, jovens e adultos. Nesse contexto, pretendemos identificar o tratamento dado às questões de língua, analisar como o professor utiliza o livro didático e verificar as relações entre a abordagem oficial e a prática pedagógica. A pesquisa é situada na Linguística Aplicada e adota procedimentos qualitativos e etnográficos. O corpus, ora restrito à fase de desenvolvimento da aula, constitui-se de informações colhidas numa escola pública estadual do ensino médio. Os resultados indicam a necessidade de intervenções na formação docente, com aprofundamento dos componentes curriculares sobre língua e sua didatização. Conclui-se que há necessidade de pesquisas e ações efetivas sobre a formação docente, no sentido de que se estabeleçam relações funcionais entre conteúdos teóricos e práticos.

- PALAVRAS-CHAVE: Língua portuguesa. Ensino médio. Aula de língua portuguesa. Concepção de língua. Prática docente. Conteúdo de ensino. Discurso de sala de aula.

\section{Introdução}

A disciplina de língua portuguesa no ensino médio tem sido o centro de questionamentos teóricos e metodológicos, em face aos níveis preocupantes dos resultados apresentados, desde a última década, pelos sistemas de avaliação educacional em andamento em nosso país, como o SAEB (Sistema de Avaliação da Educação Básica) e o ENEM (Exame Nacional do Ensino Médio), que vêm indicando sérias limitações dos egressos da educação básica quanto à leitura e à escrita em língua materna. Urge, então, que se produzam conhecimentos a respeito, os quais, ao mesmo tempo, possam explicar as razões desse fenômeno

* UnP - Universidade Potiguar. Natal - RN - Brasil. 59.022-020 - celiabarbosa@unp.br

** UFRN - Universidade Federal do Rio Grande do Norte. Departamento de Letras. Natal - RN - Brasil. 59.056000 - gonet46@yahoo.com.br 
inquietante e forneçam subsídios para propostas adequadas de intervenção. De fato, conta-se já com inúmeros estudos consistentes sobre o ensino de língua portuguesa, mas poucos voltados especificamente para sua ocorrência no ensino médio, além do que, a informação a esse respeito tende a ser mais propriamente orientada no sentido daquilo que pressupõe que a escola e os docentes devam fazer, do que daquilo que se passa, efetivamente, na prática docente. Assim, conscientes da amplitude dessa temática e dos limites práticos deste trabalho, esclarecemos que nossas reflexões situam-se numa problemática que envolve, ao mesmo tempo, as atuais políticas públicas brasileiras para a educação, a formação docente e os estudos sobre o ensino da língua materna, em face da imperativa necessidade de melhoria dos atuais níveis de alfabetização e letramento de crianças, jovens e adultos.

Considerado esse contexto, apresentamos aqui as linhas gerais de uma investigação que visa identificar o tratamento dado às questões de língua - mais propriamente, os conteúdos de ensino, analisar como o professor utiliza os recursos didáticos a sua disposição e verificar as relações entre a abordagem oficial e a prática pedagógica, no que tange à disciplina de língua portuguesa no ensino médio. Para tanto, reportamo-nos, inicialmente, à caracterização metodológica da pesquisa. Em seguida, fazemos uma breve incursão nos Parâmetros Curriculares Nacionais para o Ensino Médio - PCNEM (BRASIL, 1999) e nas Orientações Curriculares para o Ensino Médio (BRASIL, 2006), com vistas a uma melhor compreensão do que se espera para essa disciplina, nesses documentos que constituem, no momento, referências basilares para esse nível de ensino. Essa compreensão será levada em conta na análise, na medida em que configuram o ambiente discursivo em que estão situadas, institucionalmente, as práticas de sala de aula em estudo. Logo após, passamos à análise de uma amostragem de registros de aula. Trata-se de um recorte de uma investigação em que observamos por, aproximadamente, um ano e meio, o modo como a disciplina de língua portuguesa é trabalhada em duas turmas da $2^{a}$ série, do turno vespertino, de uma escola da rede pública estadual, em Natal, Rio Grande do Norte.

\section{As aulas de língua portuguesa: aspectos da investigação}

Situada no âmbito da Linguística Aplicada, a investigação contou com a participação, como informantes, de uma professora e de setenta e oito alunos. A elaboração do corpus e os procedimentos de análise seguem uma metodologia que adota aportes da etnometodologia linguística (COULON, 1995) e da etnografia escolar (FRANK, 1999; NUNAN, 2007). Ao todo, foram coletadas informações referentes a dezessetes eventos de aula, dos quais apresentaremos alguns trechos analisados, mais adiante. 
De acordo com a abordagem analítica, assumimos que as aulas podem ser caracterizadas como eventos cujos participantes interagem por meio de diferentes situações enunciativas, uma vez que orientados por objetivos distintos, o que torna seu discurso complexo e singular, sobretudo por estar associado a certas especificidades que, na análise, pareceram inerentes ao ensino e à aprendizagem da disciplina. Nessa perspectiva, pensamos o conjunto das atividades delimitadas por uma certa unidade de tempo, no espaço de certa sala de aula, como um evento genérico aqui entendido como a aula de língua portuguesa. A esse propósito, aliás, é importante lembrar que, ao definirmos essa aula como um evento, entendemos os seus vários momentos como "cenas", em que são "encenados" os vários enunciados do professor e seus alunos, em suas interações, com vistas à construção conjunta de sentidos relativos aos conteúdos de ensino em questão, em dados momentos de suas atividades verbais, orais e/ou escritas. Precisamente, reportamo-nos, aqui, à noção de "cena", encontrada em Charaudeau e Maingueneau (2008, p.95) que, ao explicarem a expressão "metáfora teatral", empregam o termo "cena" "[...] para caracterizar qualquer gênero do discurso que implica um tipo de dramaturgia [e], mais particularmente, a noção de cena para a representação que um discurso faz de sua própria situação de enunciação [...]". No caso, a aula, como evento, desenvolve-se na linha temporal numa sucessão de cenas construídas pelos interactantes, em torno de uma temática de língua portuguesa e em função dos objetivos comuns de ensino e de aprendizagem.

Ainda a esse respeito, lembramos que, ao empregar diversas metáforas para se referir aos eventos do cotidiano, Goffman (1967) compara o comportamento social à encenação teatral - daí estendermos nossa reflexão na perspectiva dos eventos do cotidiano escolar. Assim, para esse autor, o mundo seria como um teatro e, em decorrência, cada um de nós, individualmente ou em grupo, teatraliza ou é ator, consoante as circunstâncias em que nos encontramos e que são marcadas por rituais. Do mesmo modo que vimos em Charaudeau e Maingueneau (2008), Goffman (1967) também entende a interação humana a partir de uma perspectiva dramatúrgica. De fato, para ele, as formas de interação seriam tipos de espetáculo, e estes podem ser desempenhados sob a estrutura de rituais socialmente aceitáveis nas interações formalizadas - no caso presente, o evento escolar prototípico, a aula. O autor acrescenta, ainda, que a interação falada caracteriza-se como um sistema de práticas, convenções e regras de procedimentos que funcionam como um meio para guiar e organizar o fluxo da mensagem, obedecendo a fatores rituais, tais como abertura, encerramento e tópico conversacional.

É, pois, nesse sentido, que entendemos a aula de português, aqui percebida como um evento complexo e heterogêneo que se realiza a partir da diversidade dos enunciados de seus participantes, conforme os objetos de discurso em construção, ao longo da unidade de tempo a ele destinado, no espaço da sala de aula. Por 
outro lado, esse evento distingue-se (e é instituído) por um discurso caracterizado pela representação de saberes compartilhados pelos participantes, que assumem papéis relativos ao ensino, à aprendizagem, ao coleguismo e à amizade, à liderança grupal etc. Trata-se, nessa ótica, de uma espécie de encenação do ensino e da aprendizagem que se configura em forma de aula, estruturada por meio de cenas que objetivam a educação voltada para os usos institucionalizados da língua e da linguagem. A análise de algumas dessas cenas será apresentada logo adiante.

Nos dezessete eventos analisados, verificamos que algumas cenas são recorrentes, de modo que podemos configurar as aulas em quatro partes distintas, a que chamamos de fases da aula: a abertura, o desenvolvimento, os encaminhamentos para a aula seguinte e a conclusão. A esse respeito, dados os limites práticos deste artigo, restringimos nossa discussão à fase do desenvolvimento e, em seu âmbito, às cenas em que ocorrem a exposição dos assuntos (conteúdos de ensino) e os procedimentos de ensino ${ }^{1}$ relacionados com as atividades de leitura, de escrita e de correção.

\section{A disciplina de língua portuguesa no ensino médio}

A disciplina de língua portuguesa encontra-se abrigada na área de Linguagens, Códigos e suas Tecnologias. De acordo com os PCNEM (BRASIL, 1999, p.105), nessa área estão

[...] destacadas as competências que dizem respeito à constituição de significados que serão de grande valia para a aquisição e formalização de todos os conteúdos curriculares, para a constituição da identidade e o exercício da cidadania. As escolas certamente identificarão nesta área as disciplinas, atividades e conteúdos relacionados às diferentes formas de expressão, das quais a Língua Portuguesa é imprescindível.

Especificamente para a disciplina de língua portuguesa, essa área visa à constituição de competências que deverão ser trabalhadas no processo de ensinoaprendizagem, ao longo de todo o ensino médio. Por meio dessas competências, não se pretende diminuir os conhecimentos a serem adquiridos, mas sim explicar os limites nos quais o aluno desse nível de ensino venha a ter dificuldades para dar continuidade a seus estudos e participar da vida social. Ao todo são dez competências, das quais seis estão diretamente relacionadas à disciplina de língua

Lembramos, apoiados em Carlini (2004, p.26), que os conteúdos de ensino “[...] correspondem ao conjunto de fatos, informações, experiências, regras, princípios e generalizações produzidos e acumulados pela humanidade. Numa palavra, "conhecimentos.". "Os procedimentos de ensino, por sua vez, são "[...] os "o que fazer' pedagógicos, no sentido de provocar, estimular, desencadear a ação do aluno no processo de construção do conhecimento." (CARLINI, 2004, p.28). 
portuguesa, uma vez que se voltam à ideia de que toda linguagem transporta em seu interior uma visão de mundo, repleta de significados. Estes, por sua vez, ultrapassam o aspecto formal da língua, pois o estudo isolado desse aspecto, sem levar em conta a inter-relação pragmática, semântica e gramatical própria da funcionalidade da língua, desvincularia o aluno do seu caráter social. Nesse caso, a língua materna, tanto na modalidade oral como na escrita, teria o papel de viabilizar o entendimento e o encontro dos discursos empregados nas mais diversas situações da vida social:

É com e pela língua que as formas sociais arbitrárias de visão e divisão de mundo são incorporadas e utilizadas como instrumentos de conhecimento e comunicação. Aprende-se, com a língua, um 'sentido imediato de mundo', que deve ser desvendado, no decorrer de um processo de resgate desse e de outros sentidos possíveis. (BRASIL, 1999, p.131).

É, pois, dentro dessa perspectiva que, segundo esses documentos, o ensino da disciplina de língua portuguesa deve procurar desenvolver, no aluno dessa última etapa da educação básica, uma competência linguística cuja essência não se pauta na exclusividade do domínio técnico do uso da língua "padrão", mas, sobretudo, no saber empregar a língua na sua diversidade, em que se leva em consideração o contexto interativo. Neste ponto, somos levados a considerar, embora que muito brevemente, a confluência desses posicionamentos com os atuais estudos na área, que pretendem estreitar laços teóricos e metodológicos entre a linguística e o ensino da língua portuguesa, dentre os quais estão, na agenda do dia, a reflexão sobre a gramática, o texto e o discurso em situações de ensino. Dentre outros trabalhos, igualmente relevantes para informar o estado da questão, citamos, por exemplo, na linguística textual, Bentes e Leite (2010), Koch (2004, 2002a, 2002b, 1997), Marcuschi (2003), e na análise textual dos discursos, Rodrigues, Silva Neto e Passeggi (2010). Sem perder de vista os encaminhamentos teóricos e metodológicos para o ensino da língua portuguesa e, particularmente, da gramática, reportamo-nos a Antunes (2009, 2007, 2003), Dionísio e Bezerra (2003), Geraldi (2005), Kleiman (2008, 1989), Neves (2006, 2003), Travaglia (2007) eValente (2008), para ficarmos numa lista mínima, embora suficiente neste momento.

\section{O ensino da língua portuguesa: a gramática na abordagem do texto}

Na continuidade de nosso raciocínio, é oportuno frisar que nossa investigação leva em conta alguns posicionamentos sobre o ensino da língua que adotamos aqui como princípios analíticos. De fato, neste momento, considerando nosso interesse em entender a prática docente no ensino médio, é preciso retomar o fato de que ensino de língua materna tem sido objeto de questionamentos em suas abordagens 
didáticas e pedagógicas e na decorrente eficácia de suas práticas que, via de regra, confundem-se com o ensino da nomenclatura gramatical. Para Travaglia (2007), nesse contexto, costuma-se conceber gramática e texto distintamente, sem muita relação entre si, e, por isso, devem ser tratados separadamente. Para ele, esse problema está associado ao fato de se ter

[...] um ensino que parece não ter nenhuma razão ligada à vida das pessoas, uma vez que é um ensino que se estrutura apenas na perspectiva formal da identificação e classificação de unidades e estruturas da língua, esquecendo quase por completo a outra parte da gramática, que é o funcionamento da língua em textos que produzem efeitos(s) de sentido, permitindo a comunicação em situações concretas de interação comunicativa. (TRAVAGLIA, 2007, p.54).

A problemática também passa pela formação do professor, em que predomina ainda, como lembra Kleiman (2008, p.67),

[...] uma concepção tecnicista de formação que a equaciona com a apropriação de saberes de diversas áreas, entre elas as de estudos da linguagem. Assim, passou-se da análise da gramática da frase descontextualizada à gramática textual, que nada mais é, tal qual praticada em sala de aula, do que a gramática da frase exercitada a partir de trechos do texto de leitura.

Por sua vez, para ajudar a entender a questão, Travaglia (2007) lembra que a teoria linguística ou gramatical pode ser entendida em duas partes, não excludentes, em que a primeira faz parte da segunda: a) uma parte se preocupa basicamente com a identificação dos tipos de unidades e recursos de que a língua dispõe, sua classificação, identificação e estruturação; b) outra parte se preocupa basicamente com o funcionamento dessas unidades e recursos na constituição de textos para a produção de determinados efeitos de sentido (plano mais semântico e pragmático, no nível textual-discursivo).

Nessa linha de pensamento, assumimos, também, a noção de gêneros de discursos, vistos como o locus da estabilização pública e normativa que opera no quadro do sistema de gêneros de cada formação discursiva (ADAM, 2011), como base para um ensino de língua portuguesa assentado na ideia - hoje consensual nos estudos da área - de que se ponha em relevo o respeito ao saber linguístico próprio de cada um, considerando-o como princípio didático-pedagógico, enquanto garante ao aprendiz, no curso de sua intercomunicação social, o direito de ampliar, enriquecer e variar seu patrimônio linguístico e cultural. Com isso, entendemos que estudo da gramática e do texto precisa levar em conta perspectiva dos gêneros dos discursos, os quais, por sua vez, deverão ser pensados a partir de três aspectos: os gêneros de discurso, as formações sócio-discursivas 
e as relações entre contexto, cotexto e texto(s). Em decorrência imediata dessas escolhas, esta postura investigativa encontra-se apoiada em alguns pressupostos, com os quais se filia, tais como:

a) A produção de linguagem é uma complexa atividade interativa de produção de sentidos. Realiza-se com base nos elementos linguísticos presentes na superfície textual e na forma como se organizam, requerendo, para isso, não só a mobilização de um vasto conjunto de saberes, como também a sua reconstrução e a dos próprios sujeitos (KOCH, 2004).

b) O sentido de uma sequência linguística (que a transforma em texto) depende de inúmeros recursos, mecanismos, fatores e princípios internos e externos à língua. Esses elementos estão inscritos e regularizados na língua e constituem a sua gramática (TRAVAGLIA, 2007).

c) "[...] tudo o que é gramatical é textual e, vice-versa, que tudo o que é textual é gramatical. Assim, quando se estudam aspectos gramaticais de uma língua, estão sendo estudados os recursos de que a língua dispõe para que o falante/escritor constitua seus textos [...]" (TRAVAGLIA, 2007, p.45).

d) O texto é "[...] um resultado da aplicação da gramática da língua em funcionamento, para comunicar por meio da produção de efeitos de sentido [...]" (TRAVAGLIA, 2007, p.54).

e) Como argumenta Antunes (2003), numa concepção interacionista da linguagem, entende-se que, em sua funcionalidade, a língua ocorre sob a forma da textualidade, do que se admite, também, que o objeto de um ensino da língua que pretenda ser produtivo e relevante só pode ser o estudo das regularidades textuais e discursivas, na sua produção e interpretação.

f) Saber falar e escrever uma língua supõe, também, saber a gramática dessa língua e, em decorrência imediata, saber produzir e interpretar diferentes gêneros de textos. Com isso, conclui-se que as regularidades da gramática só encontram relevância e aplicabilidade no domínio do texto (ANTUNES, 2003).

Na continuidade, assumimos que tal postura teórica leva-nos, igualmente, às suas implicações metodológicas que, para o momento, podem ser resumidas em três:

1) O ensino da língua se dará na perspectiva da descrição e da reflexão linguísticas, do estudo dos gêneros textuais e da promoção do letramento, por intermédio do estudo dos mais variados textos. 
2) Ao promover o estudo do texto (em seus aspectos sintático-semânticos e composicionais), o professor será levado, necessariamente, a explorar categorias gramaticais no texto em análise. Ele deverá atentar, porém, para a função da categoria nos sentidos do texto e não para o estudo da categoria em si mesma, de modo que o objeto de estudo seja o texto, mesmo quando se estiver fazendo análise linguística de categorias gramaticais (ANTUNES, 2003).

3) Ao serem exploradas questões de gramática, a pertinência do ensino está nas condições de seus usos e nos efeitos discursivos possibilitados pelo recurso a uma ou a outra regra, o que, naturalmente, nos leva a fazer da nomenclatura um recurso, uma mediação, um ponto de passagem e não um fim, ou um objeto de estudo e, muito menos, de avaliação. Esse aspecto da abordagem é mais crítico em relação ao ensino fundamental, sobretudo nas séries iniciais. Nessa fase, é recomendável que a exploração da terminologia gramatical mereça muito pouca atenção (BRASIL, 2002; ANTUNES, 2007).

Feitas essas considerações gerais sobre a contextualização da pesquisa, apresentaremos alguns elementos de análise das aulas registradas. Não pretendendo ser exaustivos, selecionamos uma amostragem que nos parece suficiente para ilustrar a descrição e a interpretação dos registros dos eventos observados. Os resultados, apresentados em síntese logo em seguida, darão uma visão de conjunto da compreensão dessa realidade escolar, na ótica da investigação.

\section{O desenvolvimento da aula}

Em sua feição geral, a fase de desenvolvimento da aula constitui a própria concretização do que se planejou (ou se pretendeu) para o acontecimento da aula. É o momento em que o professor procura trabalhar o assunto previsto para o semestre, considerando mês, dia e horário, bem como fazer uso de uma prática pedagógica adequada à realidade de sala de aula. Esse momento configura-se na realização de várias ações, geralmente associadas a procedimentos de ensino, como aula expositiva, apresentação em grupo, dramatização, debate etc. Esses procedimentos caracterizam a prática docente e estão diretamente relacionados com a natureza dos objetivos de ensino e da interação que se estabelece entre professor e aluno e entre os próprios alunos. Essa interação, por sua vez, é considerada um fator decisivo de aprendizagem (COULON, 1995).

Em relação aos conteúdos de ensino, verificamos que, nas dezessete aulas registradas, eles constituíram tópicos de língua sobre sintaxe de concordância verbal e de colocação pronominal, assim como algumas particularidades lexicais 
e gramaticais associadas a regras da norma padrão. As aulas também versaram sobre tópicos de gêneros textuais (a carta, o conto) e de literatura (Parnasianismo e Simbolismo). Por entendermos a literatura como uma das manifestações de uso da língua, procuramos verificar de que forma o conteúdo literário era articulado com o de língua, uma vez que os conteúdos de literatura estavam inseridos na disciplina (e nas aulas) de língua portuguesa.

Quanto aos procedimentos de ensino, percebemos que a professora procurou trabalhar os conteúdos curriculares previstos, utilizando-se de uma prática pedagógica que considera atividades com o livro didático e outros livros, prática de leitura, análise e produção de texto, correção de atividades, revisão e avaliação - como prova, seminários, tarefas de produção e análise de texto. Esses procedimentos, por sua vez, foram distribuídos ao longo das dezessete aulas, considerando-se as particularidades de cada uma. Neste recorte das análises, as aulas voltam-se, sobretudo, para as atividades de leitura e escrita e de correção. Lembramos que, por razões práticas, não reproduziremos os gráficos com dados quantitativos dos questionários.

\section{A exposição dos conteúdos de ensino}

No que se refere ao conteúdo de ensino, durante o período da investigação, a professora desenvolveu suas aulas no sentido de explorar questões de uso de língua. Inicialmente, na aula 1 (A1)2 ela abordou questões relacionadas à sintaxe de concordância, particularmente "concordância do verbo ser mais adjetivo", e, na A10, de colocação pronominal, "uso da ênclise, da próclise e da mesóclise". Em seguida, na A14 e na A15, tratou sobre algumas particularidades lexicais e gramaticais da língua, como, por exemplo, o "uso dos porquês, de há/a, mal/ mau", entre outros.

Na A1, as questões que diziam respeito à "concordância do verbo ser mais adjetivo" foram expostas no quadro, por meio de regras, e copiadas pelos alunos em seus cademos, apesar de o assunto ser abordado no livro didático (SARMENTO; TUFANO, 2004), e a professora consultar essa fonte para copiar e explicar o assunto. Isso ocorreu também em outra aula, A10, na qual a professora tratou das questões relacionadas à colocação pronominal. Isso pode ser observado no fragmento 1 (F1), referente à transcrição (T) dessa aula, em que são reproduzidas as falas da professora $(\mathrm{P})$ e do aluno $(\mathrm{AO})^{3}$ :

Doravante, utilizaremos A para indicar aula, seguido do número correspondente a essa aula: A1, A2, A3 etc.

A reprodução das falas dos alunos e da professora, na transcrição das aulas, foi assim definida: $\mathbf{P}$ = professora; $\mathbf{A O}=$ aluno; $\mathbf{A A}=$ aluna. Para a reprodução da fala dos alunos, acrescentamos um algarismo que identifica a ordem das falas dos alunos na sequência dialogal com a professora, ao longo da aula. 


\section{Quadro 1 - Transcrição de Aula F1 (T-A10)}

\begin{tabular}{|c|c|c|}
\hline $\begin{array}{l}029 \\
030 \\
031 \\
032 \\
033 \\
034 \\
035 \\
036\end{array}$ & P & $\begin{array}{l}\text { Sim, na aula anterior, nós... é:.., ficamos já em algumas regras não } \\
\text { mais gerais, mas regras mais específicas, no emprego da próclise, } \\
\text { não é? E se dá quando' quando a gente observa que o emprego do } \\
\text { pronome oblíquo aparece ou nós estamos, não é? De acordo com } \\
\text { a estrutura da língua, temos co' obrigado a colocar que' pronome } \\
\text { oblíquo antes do verbo. Ênclise, a gente sabe que se coloca o } \\
\text { pronome oblíquo após o verbo. E a mesóclise, ela vai aparecer no } \\
\text { meio do verbo. }\end{array}$ \\
\hline \multirow[t]{2}{*}{037} & $\mathrm{AO} 3$ & $(?)$ \\
\hline & & {$[\ldots]$} \\
\hline $\begin{array}{l}046 \\
047 \\
048\end{array}$ & $\mathrm{P}$ & $\begin{array}{l}\text { Gente, retomando aí, o que vocês já têm copiado. Por favor! } \\
\text { Por favor, vamos só retomar! As meninas, Amanda! É:., tão, só } \\
\text { retomando aí, aquilo que a gente 'onde nós deixamos, não é? [...] }\end{array}$ \\
\hline
\end{tabular}

Fonte: Elaboração própria.

No entanto, diferentemente do procedimento adotado na exposição sobre "concordância do verbo ser mais adjetivo", na abordagem das questões acerca da "colocação pronominal", os alunos não tinham conhecimento de que esse assunto também era exposto no livro didático. Isso se deu porque a professora copiava as regras no quadro retirando-as de outra fonte (FREIRE, [20-?]) e, como ela não havia informado aos alunos que o assunto também se encontrava no livro didático, eles demonstravam desconhecer que podiam acompanhar a exposição da professora com o próprio livro. Tal fato pôde ser constatado porque, durante a explicação da professora, verificamos que nenhum aluno procurou abrir o livro, conforme podemos observar no fragmento 2 (F2), extraído do relato da aula, feito no jornal de campo (JC):
F2 (JC-A10)
O assunto é retirado de uma apostila, apesar de ser trabalhado no capítulo 37 do livro adotado (p.308-311). Os alunos até desconhecem que o referido assunto consta no livro. Verifico esse fato, pois alguns alunos estão com o livro didático sobre a mesa, mas não tiveram a curiosidade de abri-lo como já vinha procedendo em outras aulas. E, assim, copiam o que a professora escreve no quadro.

Na ocasião, verificamos que os alunos, apesar de estarem de posse, algumas vezes, do livro didático, em sala de aula, tendiam a usá-lo apenas se a professora fizesse a indicação para isso. Esse fato nos foi apontado quando aplicamos o questionário de pesquisa com os alunos e perguntamos se eles utilizavam com 
frequência o livro de português. Do universo pesquisado (quarenta alunos), 62\% responderam que faziam uso desse material com mais frequência para resolver exercícios, 55\% disseram que utilizavam o livro se a professora pedisse, e 55\% também afirmaram que o livro era frequentemente usado em época de prova. Os dados nos revelaram que o livro é mais utilizado quando a professora procura trabalhar esse material em sua prática, isto é, quando há uma maior frequência de atividades, como resolver exercícios, por exemplo. Caso contrário, passa a ser subutilizado pelos alunos.

A exposição dos conteúdos curriculares sobre questões de língua continuou, assim, a ser tratada pela professora por meio de um enfoque que tendia a ser apenas estrutural. Conforme observávamos mais intensivamente as aulas, percebíamos que os fenômenos linguísticos eram abordados levando-se em conta uma concepção de língua como um sistema virtual, abstrato, afastado do contexto real de interação, isto é, como uma língua homogênea - fato comentado anteriormente. Nesse caso, pudemos verificar que os enunciados produzidos de acordo com um modelo padrão de língua eram, algumas vezes, expostos como de "uso obrigatório", caso contrário, segundo a professora, os alunos poderiam se sentir fora do contexto de uso de uma língua tida como "ideal", desejada para atender a certas contingências de sua vida em sociedade. Logo, ao expor enunciados produzidos apenas para atender a uma variedade de uso padrão da língua, a professora concebe um ensino centrado em uma nomenclatura gramatical, o qual se caracteriza na distinção entre texto e gramática, num tipo de prática marcado pela dicotomia na abordagem desses dois domínios, reiterando, desse modo, uma problemática do ensino de língua, como discutida por Travaglia (2007).

Assim, diferentemente da proposta dos PCNEM (BRASIL, 1999), que sugerem um trabalho voltado a uma competência linguística baseada no saber empregar a língua em sua diversidade, por meio dos mais variados textos, observamos nessa exposição uma prática pedagógica que desvincula os conteúdos conceituais relativos à gramática das manifestações da língua no texto (TRAVAGLIA, 2007). Nesse caso, uma vez que o texto não é visto como unidade de ensino (BRASIL, 1999), entendemos que essa desvinculação resulta no fato de o aluno não saber empregar esses conteúdos, adequadamente, nas mais variadas formas de interação verbal, principalmente aquelas que requerem a modalidade escrita (mais próxima do uso padrão da língua). Ademais, numa abordagem interacional e sociodiscursiva da língua, entende-se que é por meio do texto que as regularidades da gramática (ANTUNES, 2003) podem ser entendidas e consideradas adequadas ou não ao uso padrão da língua, daí a pertinência de procedimentos de ensino que busquem minimizar práticas dicotômicas e excludentes relativamente aos fenômenos linguísticos e textuais. 


\title{
Os procedimentos de ensino e aprendizagem: atividades de leitura e escrita e de correção
}

As atividades de leitura e escrita foram desenvolvidas em sala de aula, e fora dela, como tarefas a serem apresentadas à professora. Em uma das atividades para casa, a professora pediu aos alunos para que copiassem o roteiro destinado à leitura e à escrita de contos. Para isso, ela lhes informou que esse roteiro nortearia os encaminhamentos para o trabalho de análise dos contos, que deveriam ter sido lidos durante as férias do meio do ano, bem como para a elaboração de um conto sob sua orientação, conforme podemos verificar no fragmento 6 (F6) do jornal de campo (JC):

\begin{abstract}
F6 (JC-A7)
Terminada a conversa, informou aos alunos que eles vão ler, analisar e produzir contos. Na oportunidade, a professora perguntou se os alunos pegaram o livro de conto na biblioteca para ler durante as férias, aliás, todo o tempo que ficaram sem aula por causa da greve (10/07 a 17/08). Eis a atividade: Roteiro de leitura e produção de contos: Ler um livro de contos observando o tempo em que os mesmos foram escritos. (Se é de $1^{a}$ pessoa ou de $3^{a}$ pessoa); Ver com atenção o clímax e o conflito da narrativa. Separar quem é o protagonista e o antagonista da história.
\end{abstract}

Em outra atividade, desta vez compreendendo a leitura e a análise de um texto em sala de aula, a professora procurou trabalhar com os alunos o conto "Carta ao prefeito", de Rubem Braga. De acordo com a professora, o conto escolhido serviria de base para que eles entendessem melhor o conceito de gênero textual e, assim, também os ajudaria na escrita dos contos da atividade de casa, tendo-o como referência, além dos outros contos sugeridos para leitura, no roteiro do trabalho.

Percebemos que, mesmo em se tratando de uma aula de língua portuguesa, cujos conteúdos tratavam de questões de língua direcionadas à organização estrutural dos enunciados na modalidade escrita, como, por exemplo, sintaxe de concordância verbal e de colocação pronominal, a professora, em nenhum momento das aulas observadas, procurou articular esse conhecimento com o dos gêneros de discurso. Nesse sentido, por exemplo, a professora poderia ter explorado o gênero carta, explorando-o a partir de traços prototípicos do gênero como também dos aspectos da organização interna de conteúdos gramaticais que lhe são específicos (KOCH, 2004). Ela poderia, ainda, ter apresentado o texto em questão como um exemplo modelar para as possibilidades de usos dos conteúdos gramaticais ali explorados, haja vista tratar-se de uma carta produzida por um falante/escritor com uma ampla competência linguística. Em linhas gerais, como sugerem Santos, Riche e Teixeira (2012), estamos pensando na possibilidade 
de adoção da abordagem "produtiva" para o ensino da língua portuguesa, que procura desenvolver as habilidades linguísticas dos alunos, uma vez que pretende aumentar o seu conhecimento sobre os recursos da sua língua por intermédio da prática de análise linguística. No entanto, ao contrário disso, o que se verificou nas práticas observadas foi um esboço de articulação de conteúdos de ensino que se restringiu apenas a uma pergunta sobre como os alunos definiriam a linguagem utilizada pelo autor do conto.

Em outra atividade de leitura e escrita, a professora entregou aos alunos o texto "As máquinas", de Bertrand Russel, e informou que eles iriam aplicar o conhecimento estudado sobre as particularidades lexicais e gramaticais. Para que pudessem analisar tais particularidades, a professora, à medida que lia o texto, pedia aos alunos para circular as palavras que deveriam ser analisadas. Além disso, lembrava-lhes que, caso desejassem trabalhar com outras palavras, eles deveriam marcar no texto e, em seguida, fazer a análise da mesma forma que haviam feito com as palavras já grifadas, anteriormente. Verificamos ainda que, mesmo em se tratando de uma atividade de leitura e escrita, em que se podia esperar, por exemplo, uma atividade de literatura articulada com a de língua, a professora, mais uma vez, procurou direcionar a atividade para que os alunos a realizassem de uma forma deslocada uma das outras. Isso pôde ser assim caracterizado porque percebíamos que os encaminhamentos para a atividade eram feitos por etapas: primeiro, a professora pedia aos alunos para analisar o sentido da palavra no texto e, por meio desse sentido, classificar qual a categoria; em seguida, ela lhes pedia para dizer qual a temática do texto e em que tempo se encontrava a narrativa. Percebemos, também, que ela tentava, às vezes, encaminhar as questões para o funcionamento da língua no texto, como sugere Travaglia (2007), mas, quando o fazia, centrava-se na palavra, vista de forma isolada.

Ao darem continuidade à atividade, verificamos que os alunos procuravam compreender por que determinadas categorias não eram mais exemplificadas como membro da categoria que eles haviam estudado. Isso ocorreu, por exemplo, com o item "daquele" ("Mas quando é desafiado a considerar a máquina do ponto de vista daqueles que têm de viver e trabalhar com ela, sua resposta é pronta [...]") que passou, durante a aula, de uma categoria de pronome demonstrativo para a de pronome indefinido. Para poder explicar ao aluno essa mudança, a professora procurava recorrer, apenas, ao aspecto semântico da palavra, dizendo que o item havia mudado de categoria porque, no texto, ele apresentava outro sentido, como podemos observar no fragmento 9 (F9) da transcrição da aula: 


\section{Quadro 2 - Transcrição de Aula F9 (T-A17)}

\begin{tabular}{|l|l|l|}
\hline 31 & AO9 & [ (?) "daquele", não é professora? \\
\hline 3233 & P & $\begin{array}{l}\text { É uma contração, porque é junção da preposição "da" mais } \\
\text { o pronome é:: INFINITIVO "aquele", certo? }\end{array}$ \\
\hline 34 & AO9 & [ Porque além do, do pronome, do pronome... \\
\hline 3536 & P & $\begin{array}{l}\text { [É uma preposição "da" mais o pronome indefinido "aquele" } \\
\text { (?) uma contração. }\end{array}$ \\
\hline 37 & AOS/AAS & ((vários alunos falando ao mesmo tempo)) \\
\hline 38 & P & Ham? "daquele" não é um pronome indefinido? \\
\hline 39 & AO9 & "Da" é o que professora, mesmo? "da"? \\
\hline 40 & P & "Da" é uma preposição. \\
\hline 41 & AO9 & Pronome indefinido (?) \\
\hline 4243 & P & $\begin{array}{l}\text { Eu digo assim: "daquele jeito não dá". Eu não, eu não estou } \\
\text { especificando de que jeito eu estou, a que jeito eu estou me } \\
\text { referindo, não é? É uma coisa inespecífica. }\end{array}$ \\
\hline
\end{tabular}

Fonte: Elaboração própria.

Nessa atividade, podemos observar, ainda, que o trabalho com a língua, particularmente na análise de itens lexicais, pode ajudar o professor a desenvolver uma prática de análise de usos linguísticos, quando baseado numa perspectiva funcional da linguagem, por intermédio da noção de protótipos (GIVÓN, 1984; CUNHA; TAVARES, 2007; TAYLOR, 1992). Ao aplicar atividade de análise de texto, por exemplo, o professor pode estimular os alunos para que aprimorem sua capacidade de compreensão e expressão, em contextos de comunicação oral ou escrita. Acreditamos que o trabalho analítico e reflexivo acerca da língua, como propõem os PCNEM (BRASIL, 1999), pode ter como ponto de partida o exame das estruturas mais regulares, percebidas no desempenho discursivo. Nesse caso, pode-se explorar ali a noção de prototipicidade, partindo-se de uma preocupação em investigar os usos linguísticos como um continuum, escalar, até chegar ao mais complexo. Por isso, "a regularidade no uso" é, nessa noção, entendida como o mais representativo, isto é, como o protótipo de uma categoria linguística.

As atividades de correção concentraram-se nas aulas A2, A3 e A16. Para o desenvolvimento dessa ação, a professora procurava dirigir-se ao centro da sala, abria o livro didático nas páginas onde se encontrava a atividade, no caso da A2 e A3, e começava a ler cada uma das questões, solicitando uma resposta aos alunos. Durante a correção de algumas dessas atividades, a professora utilizava a estratégia de perguntar à turma e não a um aluno, especificamente. A resposta era, então, retomada em uma voz coletiva, pois todos os alunos respondiam ao 
mesmo tempo, sem parar em nenhum momento para interagir com a professora sobre o porquê de sua resposta, como podemos perceber no fragmento 10 (F10) referente ao relato da aula no jornal de campo (JC):

\section{F10 (JC-A2)}

Agora, a professora levanta-se da mesa e se dirige ao meio da sala [...] Pega o livro e faz a primeira pergunta, a segunda, a terceira e assim por diante. Os alunos respondem a todas de uma vez [...] A correção é feita da seguinte maneira: a professora lê a questão e pergunta à turma.

Para não empregar só um modelo na correção da atividade, a professora procurava diversificar sua prática com uma nova estratégia. Ela direcionava, então, a pergunta a apenas um aluno e, quando este não sabia responder, ela dirigia-se a outro, que atendia prontamente à solicitação com a resposta esperada. Em seguida, a palavra era retomada pela professora para possíveis explicações, limitadas aos usos previstos e já prontos para as questões de concordância verbal encontradas no livro didático. Tanto nas aulas em que a correção fora realizada com o auxílio do livro didático, como nas em que foram revistas tarefas escritas com o conto e o texto anteriormente lidos, percebemos que essa atividade constituía-se de perguntas e respostas acompanhadas de constantes interferências, provocadas pelo barulho externo à sala de aula e pela própria interação aluno-aluno.

Durante a correção, percebíamos ainda que, para responder às questões relacionadas, por exemplo, com a concordância verbal, os alunos participavam da atividade com a professora a partir de outros usos da língua, também adequados. Tais usos eram até justificados pela professora, mas ela pedia para que os alunos não se desviassem dos usos propostos pelo livro didático. Na observação, percebia-se que a correção passava, assim, a ser vista sem muita motivação pelos aprendizes, na medida em que os enunciados tidos como certos pelo livro e reproduzidos pela professora não eram os únicos possíveis no contexto real de interação aluno-aluno. Nesse caso, estamos nos referindo às situações de comunicação do dia a dia, não idealizadas, em que o "[...] fenômeno social da interação verbal é o espaço próprio da realidade da língua [...]", conforme nos lembra Geraldi (2005, p.27).

Para os alunos, a metodologia utilizada pela professora na aula de português, que envolve as situações abordadas para explicar as questões de língua, teria uma interferência mais positiva na sua aprendizagem se fosse levado em consideração o contexto real de interação. Tal constatação deve-se ao fato de os alunos terem apontado no questionário de pesquisa que aprendem mais (grau 4,30), quando o modo de ensinar da professora faz uso, em sua explicação, de questões de língua relacionadas com a sua realidade. Por outro lado, a pesquisa nos revelou que esse 
grau tende a diminuir $(3,50)$, quando a professora trabalha com questões de usos de língua retiradas do livro didático.

Nesta altura, considerando-se nossa abordagem investigativa e nossa postura analítica, apoiadas nos princípios aqui adotados relativamente ao ensino de língua portuguesa, as análises nos levam a esboçar algumas conclusões, centradas no foco deste trabalho, quais sejam:

a) A exposição dos conteúdos curriculares sobre questões de língua foi feita por meio de um enfoque, apenas, estrutural. As questões de sintaxe sobre concordância verbal e colocação pronominal, por exemplo, foram explicadas por meio de enunciados previstos e prontos que, em muitos casos, afastavam-se dos usos ordinários da língua dos alunos, em seu cotidiano. A professora procurou enfatizar, em seu discurso, que o estudo dessas questões iria fazer com que eles aprendessem mais a língua. Contudo, o que vimos foi um ensino sem articulação com os textos que eram produzidos pelos alunos e com as questões de literatura.

b) Por meio de exercícios com questões sobre a organização estrutural da língua, os alunos são levados a corrigir suas atividades escritas com base em usos da língua já previstos e prontos, sem uma aparente motivação para refletirem sobre outros usos possíveis. Essa prática docente resulta em certa dificuldade, por parte dos alunos, quando lhes é solicitado refletir sobre o funcionamento da língua, considerando a sua diversidade de usos em textos escritos encontrados no seu cotidiano.

c) A aula de revisão do conteúdo curricular de língua e de literatura parece provocar uma maior motivação dos alunos para assistir às aulas, assim como para intensificar sua participação nas discussões. No entanto, como a professora procura trabalhar, apenas, com a leitura de regras, a motivação inicial restringe-se, em seguida, à fala da professora com uns poucos alunos próximos a ela. Entendemos que essa falta de motivação seja reflexo de uma prática docente, em que questões de língua são trabalhadas a partir de reprodução de enunciados artificialmente produzidos, atrelados à orientação de uma concepção normativo-prescritiva de ensino de língua materna que se encontrava no livro adotado. Apesar de a professora ter demonstrado em sua entrevista não gostar do livro didático, ela segue a mesma metodologia ali adotada.

d) Nas atividades de leitura, análise e produção de texto, constatamos uma prática direcionada à atividade escrita conduzida de uma forma não articulada entre leitura/produção/análise da língua, na medida em que os encaminhamentos nessas atividades são feitos por partes: primeiro, a professora pede aos alunos para examinar a palavra; depois, ela solicita-lhes que respondam qual a temática do texto e em que tempo verbal se encontram os enunciados que compõem a narrativa. Uma terceira parte é reservada para a produção de texto, sem que haja direcionamento para uma reflexão, por exemplo, com a leitura trabalhada na atividade. 


\section{Conclusões}

Diante do que vimos até aqui, o que nos ocorre, de imediato, é a imperativa necessidade de uma maior atenção na formação profissional do professor de língua, por parte de todos os segmentos institucionais envolvidos, considerandose o grau de exigências teóricas e metodológicas agenciadas na tarefa do ensino e no exercício de seu papel, na sociedade contemporânea. De modo correlato, ocorre-nos também a necessidade, igualmente imperativa, de que se explicitem, claramente, junto ao aluno, os constituintes de seu papel de aprendiz e, em particular, a razão de ser do estudo da língua (materna e/ou estrangeira) - afinal,

[...] a aprendizagem é uma construção pessoal [e essa construção] implica a contribuição por parte da pessoa que aprende, de seu interesse e disponibilidade, de seus conhecimentos prévios e de sua experiência. Em tudo isso desempenha um papel essencial a pessoa especializada [...]. (ZABALA, 1998, p.63).

Assim, diante do que viemos discutindo até então, pensamos que o problema do ensino-aprendizagem da gramática não se restringe (ou se deve) ao fato de ela ser transformada em conteúdo conceitual apenas, mas ao fato de, no processo, ela não ser pensada em sua relação com a vida de professores e alunos e, mais particularmente, com seus papéis na escola. Em qualquer intervenção que se proponha a reverter esse quadro, acreditamos que, como aparato conceitual do estudo da língua, a gramática precisa ser pensada no conjunto das funções e intenções formadoras da Educação.

No que se refere às implicações pedagógicas do texto como unidade de ensino, as atividades de ensino devem ser planejadas de modo a facilitar, no estudo escolar, a passagem do plano da gramática da língua para o plano do texto. Espera-se que resulte, daí, um incremento cognitivo (atividade mental, avanço conceitual) propiciado pela reflexão sobre o funcionamento sistêmico desses planos em sua relação com a produção de sentido. Assim, na didatização do texto mediada pelas noções da textualidade, acreditamos ser possível promover uma análise do papel dos componentes gramaticais na tecitura textual e na produção de sentido, de modo a propiciar uma melhor reflexão sobre a língua e suas manifestações discursivas identificáveis na materialidade do texto.

SILVA, C. M. M. B. da; SILVA NETO, J. G. da. The Portuguese language in high school: teaching content and class development. Alfa, São Paulo, v.57, n.1, p.295-314, 2013.

- ABSTRACT: This paper discusses how teaching content is used in Portuguese language classes, as observed in practical situations. The study follows a research aspect at the confluence of language and education studies and seeks answers to a problem involving 
current Brazilian public education policies, teacher training, and studies on mother tongue teaching, in view of the imperative need to improve current Brazilian levels of literacy for children, youth, and adults. In this context, the purpose is to identify how language issues are handled, analyze how the teacher uses the textbook, and examine relationships between the official approach and the pedagogical practice. The work is conducted under the Applied Linguistics domain, and adopts qualitative and ethnographic approaches and techniques. The corpus, focused on a class' development phase, comprises information taken from a state high school. The results point to the need for interventions in teacher education, deepening curriculum components related to language and its didactization. We conclude that there is need for research and effective actions aimed at teacher training, so that functional relations are established between theoretical and practical content.

- KEYWORDS: Portuguese. High school level. Portuguese language class. Language conception. Teaching practice. Teaching content. Classroom speech.

\section{REFERÊNCIAS}

ADAM, J.-M. A linguística textual: introdução à análise textual dos discursos. 2.ed. São Paulo: Cortez, 2011.

ANTUNES, I. Língua, texto e ensino: outra escola possível. São Paulo: Parábola Editorial, 2009.

Muito além da gramática: por um ensino de línguas sem pedras no caminho. São Paulo: Parábola, 2007.

Aula de português: encontros \& interação. São Paulo: Parábola, 2003.

BENTES, A. C.; LEITE, M. Q. (Org.). Linguística de texto e análise da conversação: panorama das pesquisas no Brasil. São Paulo: Cortez, 2010.

BRASIL. Ministério da Educação, Secretaria da Educação Básica. Orientações Curriculares para o Ensino Médio: linguagens, códigos e suas tecnologias. Brasília: MEC/SEB, 2006.

PCN + Ensino Médio: orientações educacionais complementares aos parâmetros curriculares nacionais. Brasília: MEC/SEB, 2002.

BRASIL. Ministério da Educação, Secretaria de Educação Média e Tecnológica. Parâmetros Curriculares Nacionais para o Ensino Médio. Brasília: MEC/SEMT, 1999.

CARLINI, M. Procedimentos de ensino: escolher e decidir. In: SCARPATO, M. (Org.). Os procedimentos de ensino fazem a aula acontecer. São Paulo: Ed. Avercap, 2004. p.25-83.

CHARAUDEAU, P.; MAINGUENEAU, D. Dicionário de análise do discurso. Coordenação de tradução de Fabiana Komesu. 2.ed. São Paulo: Contexto, 2008. 
COULON,A. Etnometodologia e educação. Tradução de Guilherme João de Freitas Teixeira. Petrópolis: Vozes, 1995.

CUNHA, M. A. F. da;TAVARES, M. A. (Org.). Funcionalismo e ensino de gramática. Natal: EDUFRN, 2007.

DIONÍSIO, A. P.; BEZERRA, M. A. (Org.). O livro didático de português: múltiplos olhares. 2.ed. Rio de Janeiro: Lucerna, 2003.

FRANK, C. Ethnographic eyes: a teacher's guide to classroom observation. Portsmouth: Heinemann, 1999.

FREIRE, M. de L. D. Gramática e redação: um desafio da língua. 3.ed. Assu: Studiograf, [20-?].

GERALDI, J. W. Linguagem e ensino: exercícios de militância e divulgação. Campinas: Mercado de Letras, 2005.

GIVÓN, T. Syntax: a functional typological introduction. Nova York: Academic Press, 1984. v.1.

GOFFMAN, E. Interactional ritual: essays on face-to-face behavior. New York: Anchor Books, 1967.

KLEIMAN, A. B. Concepções da escrita na escola e formação do professor. In: VALENTE, A. (Org.). Aulas de português: perspectivas inovadoras. Petrópolis: Vozes, 2008. p.67-82.

. Leitura: ensino e pesquisa. Campinas: Pontes, 1989.

KOCH, I. G. V. Introdução à linguística textual: trajetória e grandes temas. São Paulo: Martins Fontes, 2004.

. Desvendando os segredos do texto. São Paulo: Cortez, 2002a.

. Parâmetros curriculares nacionais, linguística textual e ensino de línguas. Revista do GELNE, Fortaleza, v.4, n.1, p.01-12, 2002b. Disponível em: <http://www. gelne.ufc.br/revista_ano4_no1_02.pdf>. Acesso em: 21 ago. 2011.

. O texto e a construção de sentidos. São Paulo: Contexto, 1997.

MARCUSCHI, L. A. Oralidade e ensino de língua: uma questão pouco "falada". In: DIONÍSIO, A. P.; BEZERRA, M. A. (Org.). O livro didático de português: múltiplos olhares. 2.ed. Rio de Janeiro: Lucerna, 2003. p.21-34.

NEVES, M. H. de M. Texto e gramática. São Paulo: Contexto, 2006.

Que gramática estudar na escola? São Paulo: Contexto, 2003.

NUNAN, D. Research methods in language learning. 17.ed. Cambridge: University Press, 2007. 
RODRIGUES, M. das G. S.; SILVA NETO, J. G. da S.; PASSEGGI, L. (Org.). Análises textuais e discursivas: metodologias e aplicações. São Paulo: Cortez, 2010.

SANTOS, L. W.; RICHE, R. C.; TEIXEIRA, C. S. Análise e produção de textos. São Paulo: Contexto, 2012.

SARMENTO, L. L.; TUFANO, D. Português: literatura, gramática e produção de texto. São Paulo: Moderna, 2004.

TAYLOR, J. R. Linguistic categorization: prototypes in linguistic theory. Oxford: Clarendon Press, 1992.

TRAVAGLIA, L. C. Gramática: ensino plural. 3.ed. São Paulo: Cortez, 2007.

VALENTE, A. (Org.). Aulas de português: perspectivas inovadoras. Petrópolis: Vozes, 2008.

ZABALA, A. A prática educativa: como ensinar. Porto Alegre: ARTMED, 1998.

Recebido em 30 de setembro de 2011.

Aprovado em 24 de novembro de 2012 